\title{
Research on the Effectiveness of College Students' "Going to the Countryside Engaged in Three Kinds of Service" Social Practice Activity under the Vision of Precise Poverty Alleviation
}

\author{
Xiao-dong WANG \\ College of Mathematics and Statistics, YuLin University \\ Yu Lin 719000, China
}

\begin{abstract}
College students' "going to the countryside engaged in three kinds of service" social practice activity is an important means for the effective implementation of Chinese policy of precise poverty alleviation. At present, problems such as the deviation in the ideological understanding of activity subjects, activity guarantee mechanism lags relatively behind and the lack of continuous investment in practice activity base are existing in college students' "going to the countryside engaged in three kinds of service" social practice activity. Therefore, by means of measures such as strengthening the publicity of new rural construction, innovating the educating content and means of "going to the countryside engaged in three kinds of service" and establishing a perfect social practice base project mechanism, we attempt to enhance the effectiveness of college students' "going to the countryside engaged in three kinds of service " social practice activity, so as to help our party and country to win a major victory in this battle of fighting against poverty, and provide important supporting for the realization of building a moderately well-off society in an all-round way.
\end{abstract}

Keywords-Precise poverty alleviation; Going to the countryside engaged in three kinds of service; Effectiveness

\section{INTRODUCTION}

Since our party's 18th CPC National Congress, the work of poverty alleviation and development has become the priority of priorities for the central leading body to govern the country with Xi Jingping at its core.

The General Secretary Xi Jingping particularly stressed to plan poverty alleviation and development well during the "13th Five-year" period in a scientific way, to ensure that we can be lifted out of poverty and backwardness as scheduled by the year 2020. For the work of poverty alleviation and development, preciseness and accuracy are its essence, and the focus is on the preciseness and accuracy, and the make or break lie in them. This requires us to give and launch a series of corresponding supporting policies in the aspect of materials, more importantly, we need to help them "get rid of the poverty in their mind" in the spiritual aspect [1], and cut off their "poverty root" more precisely and accurately from the root source.
As an ideological education activity in which people with advanced culture, science and technology and hygiene "going to the grass-roots units", "going to the countryside" and "being involved with common people", college students' "going to the countryside engaged in three kinds of service" social practice activity can help poor people establish a correct, positive outlook on life, on the world and values from ideological spirit in essence, which is conducive to helping the object being assisted establish a strong confidence for being lifted out of poverty, overcoming poverty and defeating it in thought. It can be seen that the group of college students is the main force of the national battle on precise and accurate poverty alleviation [2]. Therefore, the effectiveness of "going to the countryside engaged in three service" practice education activity is also related to and has an impact on the carrying forward and result of precise and accurate poverty alleviation and development.

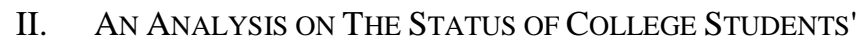
"GOING TO THE COUNTRYSIDE ENGAGED IN THREE SERVICE" SOCIAL PRACTICE ACTIVITY

As "an important path for college students to have an indepth understanding of the realistic society and take part in productive labor and social life with aims and plans.[3] "college students' "going to the countryside engaged in three services" social practice activity develops the corresponding advanced cultural educational activities by taking cultural publicity, supporting agriculture with science and technology, health care, legal aid, aiding education and eliminating illiteracy, moral practice, resources conservation and environmental protection as its theme, which greatly enriches and enhances the spiritual and cultural life of people in the service region, thus helping the poor people in the service area establish the confidence of overcoming and defeating poverty in spirit, and build up an independent and self-improvement outlook on getting rid of poverty in thought, and grasp scientific and advanced skills in ways, so as to provide a continuously powerful driving force for the transformation and enhancement of local regional economy. However, currently speaking, there exist certain problems on the actual implementation process of some college students' "going to the countryside engaged in three service" practice education 
activities, which severely constraints the playing of "going to the countryside engaged in three service" practice education activity in the national precise and accurate poverty alleviation and development. This is mainly reflected in the following several aspects;

First, there is a deviation in the ideological understanding of some students. In recent years, the number of college students engaged in summer vacation's "going to the countryside engaged in three services" has increased unceasingly. In view of the fact that colleges and universities take social practice as a compulsory course, they request to give corresponding credits after students participating in it, which leads to some students lack a general understanding of "going to the countryside engaged in three services" in thought, they do not have high enthusiasm in the practice, they lack teamwork spirit, fear hardships and fatigue, especially in the process of aid education by going to the countryside, some students fail to adapt to the conversion of their roles, as a result of this, the effect of aiding education is not good and other situations appear, so it can not truly change their understanding and concept of poverty [4]. Therefore, college students must understand the important significance of "going to the countryside engaged in three services", and participate in the activity of "going to the countryside engaged in three services" with the responsibility and mission of "being the master [5]."

Second, the guarantee link-up mechanism of "going to the countryside engaged in three service" lags relatively behind. On one hand, from social environment, "going to the countryside engaged in three service" social practice activity lack the protection of laws and policies. Up to now, China has not launched nationally unified or provincial and local laws and regulations on college students' social practice, so it is difficult to ensure the steady and healthy development of college students' social practice. On the other hand, the activity involved many aspects, and the smooth completion of "going to the countryside engaged in three service" activity cannot be completed without the guarantee on the mutual coordination and cooperation among students, the university and regional service unit. However, in the actual development process of the activity, some colleges and universities lack good communication and timely feedback with service units, thus the enthusiasm for locals or units to participate in "going to the countryside engaged in three service" activity is affected, which finally makes some places and units deem receiving college students' social practice activities as a burden, but not an important means for helping regions to be lifted out of poverty and backwardness, so they cannot provide convenient conditions for college students' social practice activities proactively.

Third, the continuously investment into "going to the countryside engaged in three service" activity base construction is insufficient. Colleges' and universities' "going to the countryside engaged in three service" activity should be continuous, that is, schools should maintain a long-time cooperation ties with service object, which is conducive to the consolidation and densification of poverty alleviation results. However, some colleges and universities ignore this kind of continuity in the process of developing "going to the countryside engaged in three service". The annual repeated conversion of activity base and area makes activity base fail to have a continuous construction, upgrading and transformation, which makes the effect of the activity greatly weakened. Of course, the objective reason for the insufficient "going to the countryside engaged in three service" activity base construction lies in the expenditure of the activity is limited. Factors such as some colleges and universities are not willing to truly support the activity by investing much money in it and the fund-raising channel of social enterprises is relatively difficult all make the activity effect be greatly discounted.

\section{PATH ON ENHANCING THE EFFECTIVENESS OF COLLEGE STUdENTS' "GOING TO THE COUNTRYSIDE ENGAGED IN THREE SERVICE" SOCIAL PRACTICE ACTIVITY}

First, we need to strengthen the publicity intensity and enhance college students' initiative and enthusiasm in taking part in practice activities by using new media. Especially in the era of new media, we need to profoundly reveal and propagate the huge significance behind the "going to the countryside engaged in three service" activity by using media information exchange platforms such as QQ, WeChat and Weibo, about which students love to see and hear, and simple words and vivid multimedia materials, guide students to have a correct understanding of their roles in this battle of getting rid of poverty, help them have a correct understanding of the connotations of college students' "going to the countryside engaged in three service" social practice, let them understand the trend of development in future, and conclude the current experience and results, so as to provide more in-depth support for the social practice. With the above efforts, in the development of the activity, college students can take the initiative to treat the activity seriously with the posture of "being the master", so they can be made to be involved in the contribution team of precise and accurate poverty alleviation and development.

Second, Innovating the content and form of "going to the countryside engaged in three service" activity by according to the specific reality of service object. The essence of precise and accurate poverty alleviation is centrally embodied in the two characters of "precise and accurate". If college students' "going to the countryside engaged in three service" social practice activity deviates from the specific reality of the service object, and if it cannot innovate the content and way of the activity practically and realistically by according to objective requirements, then it will become a mere formality, and cannot reach the fundamental requirements of precise and accurate poverty alleviation.

Therefore, we are firstly required to spend more time in the content of the activity. Especially in the process of aiding education by going to the countryside, we need to combine the professional advantages of activity subjects of different disciplines, set up the corresponding courses by according to the actual interests and hobbies of education object, by means of offering courses that are suitable for these objects, we can construct an effective bridge for communication, thus helping and guiding them build a positive spiritual world, letting them establish and stimulate the confidence of overcoming and defeating poverty in thought. 
In addition, we can expand the levels and fields of "going to the countryside engaged in three service" activity: developing from investigations, visits and observations, theatrical performances, obligatory education aid to science and technology consultation, social aid, legal consultation, anchored exercises and other higher levels. Through these more comprehensive practice investigations and observations, which attaches importance to highlight the application and conversion of knowledge economy on the basis of social benefit returns, thus it provide certain intelligent support and decision-making basis for the getting rid of poverty and becoming better off in the region of the place.

In the end, in the development form of the "going to the countryside engaged in three service" activity, on one hand, by means of service unit establishing a steady cooperation relationship with colleges and universities, local regions accept college students for conducting social practice, forming the innovative mechanism of the combination of production, studying and research, the mutually-aided training and seeking development together, we can provide high-quality human resources for service units, and inject a cardiotonic for the scientific development of the region's efforts on aiding the poor and getting rid of poverty. On the other hand, combined with the current employment situation, trying in the way of subordinated exercises and learning, and in the time period the activity is taking place, students and the local place can reach certain employment intention by going through a two-way choice mode. This not only can push forward college students' initiative and enthusiasm in taking part in social practice, which also can help local government to admit excellent college graduates and work there after graduation. Through the above innovations, the degree of attaching importance to "going to the countryside engaged in three service" by local society can be gradually improved, so as to provide support and help for the development of the "going to the countryside engaged in three service" activity [6].

Third, constructing college students' "going to the countryside engaged in three service" social practice base project mechanism. The construction of social practice base is an important guarantee for college students to conduct social practice and serve the society. In the construction of bases, we need to adhere to the principle of "jointly built and beneficial to both sides", clarity the duties and obligations of both sides, and give full play to other educational functions. We need to develop work by taking "going to the countryside engaged in three service" social practice as the strategic height for cultivating students' scientific and technological innovation, as well as enhancing their comprehensive ability. Schools should actively strive for social support, establish bases out of school, scientific research bases, establish contact with poverty alleviation points. These bases can provide places for college students to conduct social practice and exercising on one hand, they also offer students employment or self-employed opportunities. On the other hand, in the activity process, college students undertake the corresponding subject research, they put forward feasible program measures by making a careful investigation and analysis. By doing so, they help local place or enterprises solve difficult scientific and technological problems, then they make contributions to the local poverty alleviation, development and construction by giving advantages such as colleges' and universities' scientific and technological resources and talent resources.

Fourth, standardizing management investment and providing stable guarantee for "going to the countryside engaged in three service" activity. Only by means of the joint efforts, mutual coordination and improving the corresponding guarantee mechanism of governments, schools and service units, can we guarantee "going to the countryside engaged in three service" activity's advantages such as the aim is clear, the time is orderly and the organization is reasonable be realized in the poverty alleviation and development work, and can the further implementation of precise and accurate poverty alleviation can be carried out and pushed forward effectively.

\section{CONCLUSION}

Accurate poverty alleviation is both an economic battle and a political battle. With regard to precision poverty alleviation, General Secretary Xi Jinping stressed in the 19th CPC National Congress report that "we should mobilize the energies of our whole party, our whole country, and our whole society, and continue to implement targeted poverty reduction and alleviation measures. We will operate on the basis of a working mechanism whereby the central government makes overall plans, provincial-level governments take overall responsibility, and city and county governments ensure implementation; and we will strengthen the system for making heads of Party committees and governments at each level assume the overall responsibility for poverty alleviation. We will continue to advance poverty reduction drawing on the joint efforts of government, society, and the market. We will pay particular attention to helping people increase confidence in their own ability to lift themselves out of poverty and see that they can access the education that they need to do so. We will strengthen collaboration on poverty alleviation between the eastern and western regions; and we will provide focused assistance to areas of extreme poverty. We must ensure that by the year 2020, all rural residents living below the current poverty line have been lifted out of poverty, and poverty is eliminated in all poor counties and regions. Poverty alleviation should reach those who truly need it and deliver genuine outcomes. "colleges and universities, as the party's education input, research incubation base and cultural gathering place, should respond to the general secretary's call for accurate poverty alleviation, through the party committee and the Communist Youth League, actively integrate the internal resources of colleges and universities, coordinate the government and enterprises, to promote the "three rural areas" social practice of college students during the summer vacation.

\section{REFERENCES}

[1] Xi Jinping. Getting Rid of Poverty [M]. Fujian: Fujian People's Press,2014, 08.

[2] Zhu Chuanqi.College Students' "Going to the Countryside Engaged in Three Kinds of Service" social practice activity\&new countryside construction[J].Reform \& Openning.2011.20.101.

[3] Zhang Kunjin. College Students' Aiding in Education to Assist Precise and Accurate Poverty Alleviation [J]. Inheritance, (8), 2016. 
[4] Chen Xuhua.College Students' "Going to the Countryside Engaged in Three Kinds of Service" social practice activity' s problems and countermeasures $[\mathrm{J}]$. Journal of Shandong Administration Institute \& Shandong Economic Management Personnel Institute. Jun.2009, NO.3Ser.No.98
[5] Zhang Hanyue. 'internet plus'Precise Poverty Alleviation:research on the mode of poverty alleviation in local normal universities[J].Primary and Middle School Educational Technology, 2017,09.

[6] Ren Xu.What can college students do in "Going to the Countryside Engaged in Three Kinds of Service" social practice activity[J]. 2017.29(10). 